\title{
Ovarian Granulosa Cell Tumors: A Retrospective Study of 21 Cases and a Review of the Literature
}

\author{
Imtinane Belaid ${ }^{1 *}$, Mghirbi Fahmi ${ }^{1}$, Jaidane Lilia ${ }^{2}$, Makrem Hochlaf $^{1}$, Faten Ezairi ${ }^{1}$, Imene Chabchoub $^{1}$, \\ Leila Ben Fatma ${ }^{1}$, Moncef Mokni ${ }^{2}$, Hedi Khairi ${ }^{3}$ and Slim Ben Ahmed ${ }^{1}$
}

${ }^{1}$ Department of Medical Oncology, Farhat Hached University Hospital, Université de Sousse, Faculté de Medecine de Sousse, Tunisia

${ }^{2}$ Department of Pathology, Farhat Hached University Hospital, Université de Sousse, Faculté de Medecine de Sousse, Tunisia

${ }^{3}$ Department of Gynaecology and Obstetrics, Farhat Hached University Hospital, Université de Sousse, Faculté de Medecine de Sousse, Tunisia

*Corresponding author: Belaid Imtinane, Department of medical Oncology,

Hopital Farhat Hached, Ibn El Jazzar street, Sousse, Tunisia.

Received Date: September 26, 2018

Published Date: October 11, 2018

\begin{abstract}
Background: Granulosa cell tumors are rare tumors with a relatively favorable prognosis. The aim of this study was to report the epidemiologic, anatomo-clinical characteristics and to determine treatment modalities and survival rates.

Methods: We retrospectively analyzed data from patients treated for granulosa cell tumors in our hospital over a 17-year period (1998-2015).

Results: Twenty-one cases were retrieved. The median age was 52 years. The most common clinical manifestations at diagnosis were post-menopausal bleeding and pelvic pain. Mean tumor size was $10 \mathrm{~cm} .76 .2 \%$ of the patients were diagnosed with a stage I disease. One patient (4.8\%) underwent unilateral salpingo-oophorectomy, 4 patients (19\%) underwent a total hysterectomy with unilateral salpingo-oophorectomy, while 15 patients (71.4\%) underwent a total hysterectomy with bilateral salpingo-oophorectomy. One patient had only a biopsy. Relapse rate was $14.3 \%$ and the latest recurrence was seen 60 months after surgery. Actuarial 10 -year relapse free survival (RFS) and overall survival (OS) were $85.7 \%$ and $90.5 \%$ respectively.
\end{abstract}

Conclusion: Granulosa cell tumor of the ovary is an uncommon neoplasm. The adult form progresses slowly and is often diagnosed in an early stage of disease. Surgery is the mainstay of treatment. A prolonged post-therapeutic follow-up is necessary because very late recurrences have been reported.

Keywords: Drug therapy; Granulosa cells; Ovarian neoplasms; Surgery

\section{Background}

Ovarian granulosa cell tumors (GCT) are very rare ovarian neoplasms that derived from sex cord cells. They represent $2-5 \%$ of all ovarian cancers [1,2]. GCT are divided into 2 subgroups: juvenile and adults GCT depending on clinical presentation and histological characteristics. These types represent respectively 5 and $95 \%$ of all the GCT [1,3]. In comparison to epithelial ovarian cancers, they are characterized by an early age of diagnosis and a good prognosis [3-6]. Complete surgical resection is the mainstay of treatment [7]. The role of adjuvant chemotherapy is controversial particularly in patients with stage II disease. Recurrence could occur up to 40 years after treatment [8].

The aim of this study is to report the epidemiologic, anatomoclinical characteristics and to determine treatment modalities, survival rates, and prognostic factors.

\section{Methods}

This retrospective study was conducted in the Department of Oncology in Farhat Hached Hospital based in Sousse, Tunisia over a 17-year period, from 1998 to 2015. This study included 21 cases of female patients with histological evidence of GCT. Anatomoclinical characteristics (age, parity, menopausal status, symptoms, diameters of tumors, stage of disease) as well as biological, radiological, and pathological data were analyzed. Type of surgery, adjuvant chemotherapy and relapse rate were also noted. Disease free survival (DFS) time was calculated as the number of months from the date of surgery to either the date of recurrence or date censored. Overall survival (OS) time was calculated as the number of months from the date of surgery to the date of death or date censored. Survival curves and rates were calculated using the 
Kaplan-Meier method and were compared using the log rank test. Two-sided p-values less than 0.05 were considered statistically significant. All statistical analyses were performed using SPSS software for Windows 22.0.

\section{Results}

Twenty-one women with a diagnosis of GCT of the ovary were identified during this study period. Patients' characteristics are detailed in table. The median age of the patients was 52 years (range 11-86 years) and $57.2 \%$ of the patients were postmenopausal women. The median body mass index (BMI) was 22 $\mathrm{kg} / \mathrm{m} 2\left(17-35 \mathrm{~kg} / \mathrm{m}^{2}\right)$. Two patients had a decrease in performance status (grade 2 and 3 ). The median time to diagnosis was 5 months (range 1-36). The most common initial presenting symptom was post-menopausal bleeding (47.6\%). The other symptoms were pelvic pain and abnormal distension (33\% and $9.5 \%$ respectively). The average tumor size was $10 \mathrm{~cm}(4-28 \mathrm{~cm})$.

In abdominal ultrasound, we identified three morphologies: unilocular cystic, solid and cystic, and solid. The most common morphology was multicystic $(n=10,47.6 \%)$. The next most common was solid and cystic $(n=7,33.3 \%)$. The remainder were solid $(n=$ $3,14.3 \%)$.

Two patients had a normal level of estradiol. None of the patients had a pre-operative cancer antigen 125 (CA125) or an inhibin level for evaluation.

All patients in this study underwent initial laparotomy surgery. Decision of extent of surgery was dependent on the age of the patient and desire for future fertility. One patient (4.8\%) underwent unilateral salpingo-oophorectomy, 4 patients (19\%) underwent a total hysterectomy with unilateral salpingo-oophorectomy, while 15 patients $(71.4 \%)$ underwent a total hysterectomy with bilateral salpingo-oophorectomy. One patient had only a biopsy because of a locally advanced disease.

Adult GCT was the most common histological subtype, only one patient had a juvenile GCT. A lymph node dissection was performed in only three patients. Lymph nodes were not histologically invaded in these three cases. Fourteen (66.6\%) patients had a histological examination of the endometrium (biopsy or resected specimen). The results were as follows: nine (65.3\%) were negative, four (28.5\%) were hyperplasic, and one patient had an endometrial adenocarcinoma.

The staging breakdown was as follows: stage I $(76.2 \%, \mathrm{n}=16)$, stage II $(4.8 \%, \mathrm{n}=1)$, stage III $(14.3 \%, \mathrm{n}=3)$, and stage IV $(4.8 \%, \mathrm{n}$ $=1)$.

Five patients $(23.8 \%)$ received adjuvant chemotherapy with a median of 4 cycles (3-6). Three patients received bleomycin, etoposide, and cisplatin regimen (BEP) and one patient had an EP regimen. Etoposide, ifosphamide and cisplatin (VIP) regimen was administered for one patient who had the juvenile type granulosa. One patient received two lines of palliative chemotherapy (BEP and VIP) for a locally advanced and pulmonary metastatic disease. In our study, three patients developed disease recurrence (metastatic, abdominal parietal and contralateral) and were treated by chemotherapy followed by surgery in two cases. The most serious adverse events reported with chemotherapy were neutropenia (4 patients) which was complicated in one case by a necrotizing enterocolitis. The other reported side effects were mucositis (1 patient) and alopecia (3 patients).

Mitotic rate was measured in only 11 patients: four patients had a low mitotic index, three had an intermediate one and four had a high mitotic count. Call Exner bodies were seen in 9 cases.

Actuarial 10-year relapse free survival (RFS) and overall survival (OS) were $85.7 \%$ and $90.5 \%$ respectively (Figures 1 \& 2).

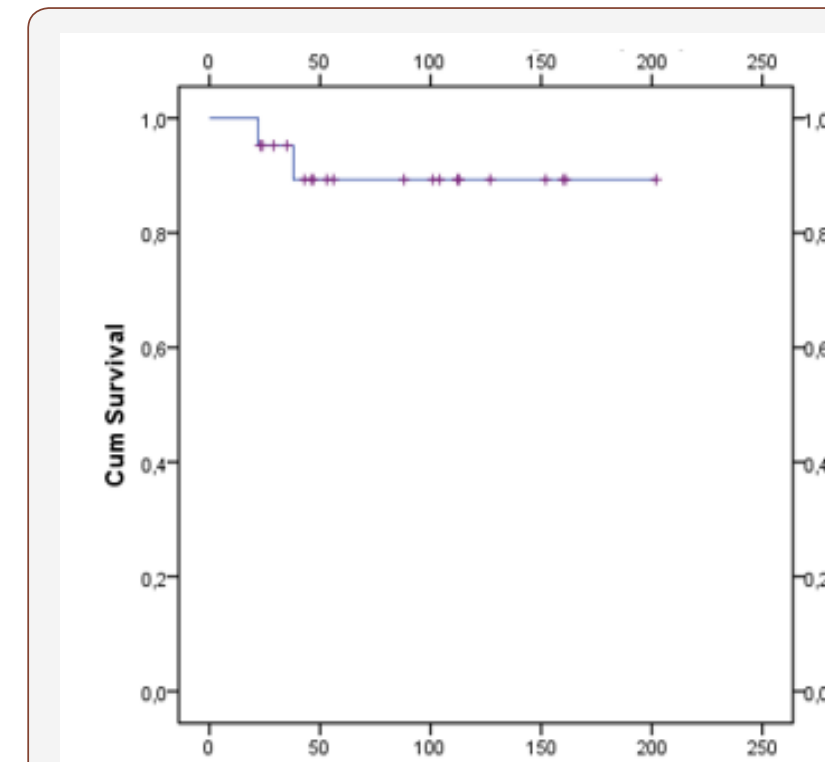

OS (months)

Figure 1: overall survival of patients with GCT in our study.

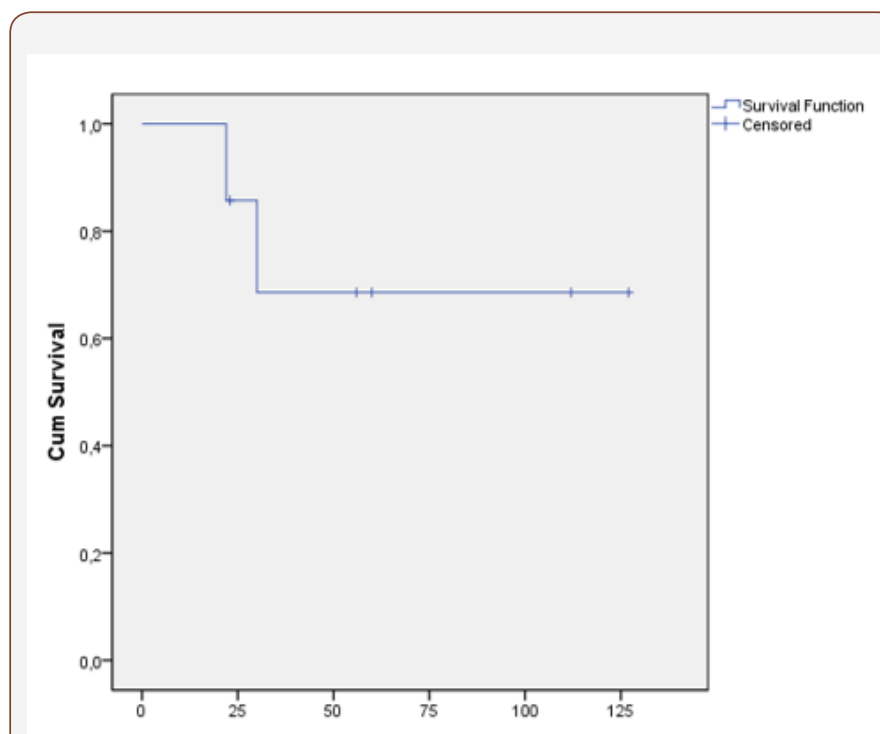

RFS (months)

Figure 2: Relapse free survival of patients with GCT in our study.

Age, BMI, performans status, FIGO stage, menopause, lymph node dissection, adjuvant chemotherapy, Call-Exner bodies, mitotic index, tumor size, bilaterality and rupture were not associated with OS and RFS. 


\section{Discussion}

\section{Diagnosis and work-up}

GCT is a rare ovarian cancer that affects mostly post-menopausal women with a median age ranging between 47 and 57 years [3-6]. As in our study, the most frequent symptoms include menstrual disturbance, abdominal pain, distension and bloating which are due to the large size of the tumor. Endocrine manifestations (pseudo puberty, galactorrhea) may complete the clinical presentation. They are noted in $66 \%$ of the patients [9]. In our study, none of the patients complained of these symptoms. Previous studies showed tumors larger than $30 \mathrm{~cm}$ and the median $10.8-11.8 \mathrm{~cm}[4,10]$. Our study finds tumor larger than $10 \mathrm{~cm}$ in $57.1 \%$ of the case and a mean of $10 \mathrm{~cm}$

Because of the endogenous estrogen effect, endometrial hyperplasia is also frequently present. Approximately $25-50 \%$ of GCTs is associated with endometrial hyperplasia, whereas 5-13\% is associated with an endometrial carcinoma $[1,3,5,11,12]$. In our study, a case of endometrial adenocarcinoma was found in the final pathological examination after total hysterectomy.

Ultrasound and CT scan are used for the assessment of tumor morphology and for the diagnostic work up. In the majority (70\%) of the cases GCTs are described as mixed solid and cystic. The second most common morphology was multicystic (16\%) [13]. Solid and unilocular aspects are very uncommon. In our study, most cases were found to be multicystic tumors (47.6\%).

The serum tumor markers are estradiol, inhibin, and antiMüllerian hormone [14]. CA125 is not sensitive enough to serve as tumor marker in this disease. Concerning inhibin, its value may be correlated to the tumor mass, with an increased level of inhibin in serum preceding clinical relapse and was a more reliable tumor marker of disease activity than estradiol $[15,16]$. Actually, estradiol is not produced in approximately $30 \%$ of GCT.

\section{Treatment}

Surgery is the cornerstone of the treatment of GCT. A vertical midline or paramedian incision is performed to allow adequate exploration of the pelvis and the upper abdomen. A complete surgical resection with a total abdominal hysterectomy and bilateral salpingo-oophorectomy should be performed for postmenopausal women and for those whose fertility is not an issue [7]. For young patients who want to preserve fertility and if the tumor appears to be confined to one ovary, a unilateral salpingo-oophorectomy could be performed $[7,17]$. Omentectomy, samples of multiple intraperitoneal site biopsy and endometrial biopsy should be performed prior to sending samples to pathology. Lymphadenectomy is not recommended, it has not been proven to prolong survival $[17,18]$. In our study, lymph node dissection was performed in three patients and was not associated with OS and RFS.

Single agents such as doxorubicin and cyclophosphamide were found to have only modest activity in GCT, whereas platinumcontaining combination chemotherapy regimens were more active $[4,19]$. The most used chemotherapy regimen is a BEP (bleomycin, etoposide, and cisplatin) regimen [9]. In our study, this type of chemotherapy was used in $62.5 \%$ of the cases.

When the disease could not be completely resected, prognosis is poorer $[20,21]$. These patients had usually been treated with chemotherapy, with the intent to make the tumor resectable. The largest prospective phase II trial involving 75 patients with unresectable disease treated with BEP was conducted by the Gynecologic Oncology Group [22]. Among 25 patients evaluable for clinical response, 10 responded $(\mathrm{RR}=40 \%)$ and $14(56 \%)$ achieved stable disease. A clinical complete response was shown in $24 \%$ of them, whereas a pathological complete response at the time of second-look laparotomy was found in $37 \%$ (14 out of 38 patients). After 3 years of median follow-up, $44 \%$ of patients had a recurrence and $17 \%$ had died of disease, including 3 pathologically complete responders (at 15.4, 20.1 and 68.7 months).

Only one study has shown a survival benefit of postoperative BEP chemotherapy in patients with stage III- IV GCT [23]. Patients achieved optimal cytoreduction and received at least six cycles of BEP postoperative chemotherapy.

It is difficult to evaluate the role of adjuvant chemotherapy in patients with stage I-II disease because of the rarity of this tumor and the absence of prospective randomized studies. Some retrospective studies showed no difference in DFS between patients with early-stage (I-II) GCT who received adjuvant chemotherapy and those who were only followed up.

Patients with stage I disease have an excellent prognosis (longterm disease-free status is about 90\%) and for many authors do not require further adjuvant treatment $[1,4,11,24]$. In premenopausal women with stage IA disease who had conservative surgery, adjuvant chemotherapy does not seem to confer any benefit too $[3,25,26]$. However, some stage I disease patients with large tumor size, tumors with high index mitotic or ruptured tumors may have a higher risk of relapse and may require post-operative chemotherapy [9,27-29].

Hormonal manipulation of GCT arise from the surmise that suppression of endogenous estrogen will provide an antiproliferative milieu which could be effective in treating GCT. The hormonal therapy based on Megestrol, Tamoxifen, Aromatase inhibitors and LHRH (luteinizing hormone-releasing hormone) agonists also lead to good responses in some cases, particularly for recurrent disease $[25,30]$.

In a study of 45 cases of GCT, Foutopoulou [9] reported that there was $43 \%, 72 \%$, and $89 \%$ expression of ER (estrogen receptor), PR (progesterone receptor) and inhibin respectively while in the recurrent setting there was $91 \%, 91 \%$, and $65 \%$ respectively.

Prolonged remission (14-42 months) [31,32] have been documented in patients having extensive disease treated with high doses of medroxyprogesterone acetate (100-300 mg thrice daily). Similarly, Briasoulis et al. [33] reported partial response lasting 20 months after megestrol acetate (160 mg four times a day) was given to an elderly lady with lung metastasis. 
Hardy et al. [22] documented a complete response at 22 months and a disease-free-interval of 5 years by alternating bi-weekly cycles of megestrol acetate ( $40 \mathrm{mg}$ twice daily) with tamoxifen (10 mg twice daily) in a patient with recurrent ER negative PR positive GCT. Continuous progesterone exposure leads to depletion and down regulation of PRs in target tissues while Tamoxifen increases PR concentration. Thus, sequential therapy may prolong the antiproliferative effects of progestin by allowing regeneration and stimulation of PRs.

The use of Anastrozole (1 mg/day) and Letrozole (2.5 mg/day) in recurrent GCT have been reported with remissions ranging from 12 to 54 months [34-36].

The effectiveness of monthly GnRH agonists is controversial. Many studies $[18,34,37,38]$ have described partial response with Leuprolide acetate (3.75 mg IM) lasting 3-13 months. However, other authors showed no response to GnRH agonists.

Radiotherapy has been used in the adjuvant setting $[24,39,40]$. Hauspy et al. [18] showed that women who received postoperative radiotherapy had a significant lower risk of disease recurrence compared with those who were treated with surgery alone ( $p$ value 0.04). However, no randomized trials exist for defining the role of radiotherapy in the treatment of GCTs.

The vascular nature of GCT makes it susceptible to inhibition of angiogenesis. Tao et al. [41] evaluated eight patients treated with bevacizumab, a VEGF inhibitor. The overall response rate was $38 \%$ and clinical benefit rate was $63 \%$. Although only one patient had a complete response, the median PFS of 7.2 months was similar to the PFS of 6.8 months after taxanes and 11.2 months after BEP seen in patients with recurrent GCT [9].

Kalfa et al. [42] identified a mutation of FOXL2 (transcription factor gene) in the majority of granulosa cell tumors, particularly in the adult form. Yoo et al. [43] also identified mutations of genes Fas, FLIP and Bcl- 2 related to alterations of apoptosis. These mutations could be the next targets for use in treatment.

Rico et al. [44] demonstrated an increase in mTOR (mammalian target of rapamycin) deregulation by using a mouse model with granulosa cell tumors. So, targeting mTOR may be beneficial to women with granulosa cell tumors. More studies will be necessary.

GCT is known to have a good prognosis. The 5-year OS reported in the literature ranges between $77-92 \%$, the 10 -year OS between $76-85 \%$. The stage of the tumor is the only clinical factor unequivocally related to survival rate [3-5]. Patients with stage I disease have a very favorable outcome, with reported survival rates of $93-100 \%$ at 5 years, $75-88 \%$ at 10 years, $75 \%$ at 15 years and $62 \%$ at 20 years $[10,11,13,44]$. The 5 -year survival rates for patients with stage II GCT have been reported to range from $55 \%$ to $75 \%[4,7]$. Patients with more advanced disease have a much worse prognosis (5-year survival rate ranges between 33-44\%) [45]. The number of mitoses is also a recognized prognostic factor. Ala Fossi et al. [46] showed that p53 mutation was significantly correlated to survival. Actually, patients with no mutations had a 10 times higher survival than those with mutations.
GCTs have a tendency for recurrence even many years after remission. Recurrence rates reported in the literature ranges between 5.3 and 33\% [23,47-49]. Ahyan's study of 80 patients with granulosa cell tumors, revealed recurrence rates of $5.4 \%, 21 \%$ and $40 \%$ for stage I, stage II and stage III, respectively [50]. Patients in our study had a relapse rate of $14.3 \%$ (Figure 2). The longest reported time to recurrence is 40 years. The median RFS reported in some studies ranges between 44-50 months [51]. In the study of Savage et al. [22], patients with stage I disease were relapsefree for a median of 76 months. Several risk factors for recurrence after surgery for GCT have been suggested, although some of them are not observed consistently. These include advanced age $[4,20]$, advanced stage at diagnosis [4,9,17], bilaterality, large tumor size $[1,3,9,11,52]$, tumor rupture or malignant ascites $[4,25,53]$, lymphatic space invasion [4], presence of residual disease [4,52,53], high mitotic index (>10/10 HPF) [4,5,11,20,53,54], absence of CallExner bodies [45], DNA ploidy [55], nuclear atypia [49,50], diabete [48] and Ki-67 [56] and p53 expression [54]. In our study, a number of prognostic factors were tested but none of them was found to be correlated to recurrence.

\section{Conclusion}

GCTs are uncommon ovarian neoplasms. They are characterized by a good prognosis and affects mostly post-menopausal women. Complete surgical resection with a total abdominal hysterectomy and bilateral salpingo-oophorectomy is the mainstay of treatment. For young patients who want to preserve fertility and if the tumor appears to be confined to one ovary, a conservative surgery could be performed. Patients with advanced stage may be treated with chemotherapy based on platinum containing regimens with at least six cycles of BEP after optimal cytoreduction. Locally advanced recurrences could be treated by chemotherapy, hormonal agents, targeted therapy or some combination of strategies with the intent to make the tumor resectable. Research in the molecular pathogenesis of GCT can shed light on various prognostic factors and therapeutic agents which can be effective in the adjuvant and palliative setting.

\section{References}

1. Evans AT 3rd, Gaffey TA, Malkasian GD Jr, Annegers JF (1980) Clinicopathologic review of 118 granulosa and 82 theca cell tumors. Obstet Gynecol 55(2): 231-238.

2. Unkila-Kallio L, Tiitinen A, Wahlström T, Lehtovirta P, Leminen A (2000) Reproductive features in women developing ovarian granulosa cell tumour at a fertile age. Hum Reprod 15(3): 589-593.

3. Fox H, Agrawal K, Langley FA (1975) A clinicopathologic study of 92 cases of granulosa cell tumor of the ovary with special reference to the factors influencing prognosis. Cancer 35(1): 231-241.

4. Khosla D, Dimri K, Pandey AK, Mahajan R, Trehan R (2014) Ovarian granulosa cell tumor: clinical features, treatment, outcome, and prognostic factors. N Am J Med Sci 6(3): 133-138.

5. Malmström H, Högberg T, Risberg B, Simonsen E (1994) Granulosa cell tumors of the ovary: prognostic factors and outcome. Gynecol Oncol 52(1): 50-55.

6. Schumer ST, Cannistra SA (2003) Granulosa cell tumor of the ovary. J Clin Oncol 21(6): 1180-1189.

7. Colombo N, Parma G, Zanagnolo V, Insinga A (2007) Management of ovarian stromal cell tumors. J Clin Oncol 25(20): 2944-2951. 
8. Nadeau ME, Kaartinen MJ, Laguë MN, Paquet M, Huneault LM, et al. (2009) A mouse surgical model for metastatic ovarian granulosa cell tumor. Comp Med 59(6): 553-556.

9. Yim GW, Kim YT (2011) Granulosa cell tumor of the ovary: time to launch a new prospective trial. J Gynecol Oncol 22(3): 143-144.

10. Tamura R, Yokoyama Y, Yanagita T, Matsumura Y, Abe K, et al. (2012) Presentation of two patients with malignant granulosa cell tumors, with a review of the literature. World J Surg Oncol 10:185.

11. Stenwig JT, Hazekamp JT, Beecham JB (1979) Granulosa cell tumors of the ovary. A clinicopathological study of 118 cases with long-term follow-up. Gynecol Oncol 7(2): 136-152.

12. Gusberg SB, Kardon P (1971) Proliferative endometrial response to theca-granulosa cell tumors. Am J Obstet Gynecol 111(5): 633-643.

13. Stine JE, Suri A, Gehrig PA, Chiu M, Erickson BK, et al. (2013) Preoperative imaging with CA125 is a poor predictor for granulosa cell tumors. Gynecol Oncol 131(1): 59-62.

14. Geerts I, Vergote I, Neven P, Billen J (2009) The role of inhibins B and antimüllerian hormone for diagnosis and follow-up of granulosa cell tumors: Int J Gynecol Cancer 19(5): 847-855.

15. Burger HG, Baillie A, Cahir NF, Drummond AE, Gurusinghe CJ, et al. (1997) Production of inhibin-related peptides by ovarian tumors. Inhibin, Activin and Follistatin: 162-169.

16. Boggess JF, Soules MR, Goff BA, Greer BE, Cain JM, et al. (1997) Serum inhibin and disease status in women with ovarian granulosa cell tumors. Gynecol Oncol 64(1): 64-69.

17. Thrall MM, Paley P, Pizer E, Garcia R, Goff BA (2011) Patterns of spread and recurrence of sex cord-stromal tumors of the ovary. Gynecol Oncol 122(2): 242-245

18. Kottarathil VD, Antony MA, Nair IR, Pavithran K (2013) Recent advances in granulosa cell tumor ovary: a review. Indian J Surg Oncol 4(1): 37-47.

19. Vani BR, Geethamala K, Geetha RL, Srinivasa MV (2014) Granulosa cell tumor of ovary: A clinicopathological study of four cases with brief review of literature. J Life Health 5(3): 135-138.

20. Bristow RE, Karlan BY, Chi DS (2015) Surgery for ovarian cancer: Principles and practice. ( $3^{\text {rd }}$ edn), CRC Press, USA, p. 437.

21. Cerbonnet G, Rochet Y, Bethoux JP (1986) Les traitement des tumeurs de l'ovaire: rapport présenté au 88e Congrès français de chirurgie, Paris.

22. Teoh D, Freedman R, Soliman PT (2010) Nearly 30 years of treatment for recurrent granulosa cell tumor of the ovary: a case report and review of the literature. Case Rep Oncol 3: 14-18.

23. Park JY, Jin KL, Kim DY, Kim JH, Kim YM, et al. (2012) Surgical staging and adjuvant chemotherapy in the management of patients with adult granulosa cell tumors of the ovary. Gynecol Oncol 125(1): 80-86.

24. Savage P, Constenla D, Fisher C, Shepherd JH, Barton DP, et al. (1998) Granulosa cell tumours of the ovary: demographics, survival and the management of advanced disease. Clin Oncol (R Coll Radiol) 10(4): 242 245.

25. Auranen A, Sundström J, Ijäs J, Grénman S (2007) Prognostic factors of ovarian granulosa cell tumor: a study of 35 patients and review of the literature. Int J Gynecol Cancer 17(5): 1011-1018.

26. Shimizu K, Yamada T, Ueda Y, Yamaguchi T, Masawa N, et al. (1999) Cytologic features of ovarian granulosa cell tumor metastatic to the lung. Acta Cytol 43(6): 1137-1141.

27. Ranganath R, Sridevi V, Shirley S S, Shantha V (2008) Clinical and pathologic prognostic factors in adult granulosa cell tumors of the ovary. Int J Gynecol Cancer 18(5): 929-933

28. El Mehdi T, Essadi I, M'rabti H, Errihani H (2011) Rare recurrence of a rare ovarian stromal tumor with luteinized cells: a case report. J Med Case Reports 5: 350 .

29. Sehouli J, Drescher FS, Mustea A, Elling D, Friedmann W, et al. (2004) Granulosa cell tumor of the ovary: 10 years follow-up data of 65 patients. Anticancer Res 24(2C): 1223-1229.
30. Nick Zagorski (2005) Profile of Xiaodong Wang. Proc Natl Acad Sci USA 103(1): 7-9.

31. Adamietz IA (1997) Radiation Oncology of Gynecological Cancers. Springer Science \& Business Media, Berlin, Germany.

32. Garcia-Donas J, Hurtado A, García-Casado Z, Albareda J, López-Guerrero JA, et al. (2013) Cytochrome P17 inhibition with ketoconazole as treatment for advanced granulosa cell ovarian tumor. J Clin Oncol 31(10): e165-e166.

33. Briasoulis E, Karavasilis V, Pavlidis N (1997) Megestrol activity in recurrent adult type granulosa cell tumour of the ovary. Ann Oncol 8(8): 811-812.

34. Kim HJ, Lee SC, Bae SB, Kwon KW, Kim CK, et al. (2009) GnRH against therapy in a patient with recurrent ovarian granulosa cell tumors. J Korean Med Sci 24(3): 535-538.

35. Korach J, Perri T, Beiner M, Davidzon T, Fridman E, et al. (2009) Promising effect of aromatase inhibitors on recurrent granulosa cell tumors. Int J Gynecol Cancer 19(5): 830-833.

36. Abdul Munem A, Al-Bahrani B, Mehdi I, Kamona A, Nadas AM (2012) Aromatase inhibitors--a viable option for recurrent granulosa cell tumour of ovary: overview and case report. J Pak Med Assoc 62(5): 505507.

37. van Meurs HS, van Lonkhuijzen LR, Limpens J, van der Velden J, Buist MR (2014) Hormone therapy in ovarian granulosa cell tumors: a systematic review. Gynecol Oncol 134(1): 196-205.

38. Sekkate S, Kairouani M, Serji B, Tazi A, Mrabti H, et al. (2013) Ovarian granulosa cell tumors: a retrospective study of 27 cases and a review of the literature. World J Surg Oncol 11: 142.

39. Pankratz E, Boyes DA, White GW, Galliford BW, Fairey RN, et al. (1978) Granulosa cell tumors. A clinical review of 61 cases. Obstet Gynecol 52(6): 718-723.

40. Wolf JK, Mullen J, Eifel PJ, Burke TW, Levenback C, et al. (1999) Radiation treatment of advanced or recurrent granulosa cell tumor of the ovary. Gynecol Oncol 73(1): 35-41.

41. Tsoi M, Laguë MN, Boyer A, Paquet M, Nadeau MÈ, et al (2013) AntiVEGFA therapy reduces tumor growth and extends survival in a murine model of ovarian granulosa cell tumor. Transl Oncol 6(3): 226-233.

42. Kalfa N, Veitia RA, Benayoun BA, Boizet-Bonhoure B, Sultan C (2009) The new molecular biology of granulosa cell tumors of the ovary. Genome Med 1(8): 81.

43. Yoo NJ, Kim MS, Lee SH (2012) Expression and mutation analyses of Fas, FLIP and Bcl-2 in granulosa cell tumor of ovary. Tumori 98(5): $118 \mathrm{e}-121 \mathrm{e}$

44. Rico C, Laguë MN, Lefèvre P, Tsoi M, Dodelet-Devillers A, et al. (2012) Pharmacological targeting of mammalian target of rapamycin inhibits ovarian granulosa cell tumor growth. Carcinogenesis 33(11): 22832292.

45. Berek JS, Hacker NF (2010) Berek and Hacker's Gynecologic Oncology. Lippincott Williams \& Wilkins, USA, p. 895.

46. Wang WC, Lai YC (2014) Molecular pathogenesis in granulosa cell tumor is not only due to somatic FOXL2 mutation. J Ovarian Res 7: 88.

47. Pectasides D, Pectasides E, Psyrri A (2008) Granulosa cell tumor of the ovary. Cancer Treat Rev 34: 1-12.

48. Suri A, Carter EB, Horowitz N, Denslow S, Gehrig PA (2013) Factors associated with an increased risk of recurrence in women with ovarian granulosa cell tumors. Gynecol Oncol 131(2): 321-324.

49. Rebstock LE, Leufflen L2, Leroux A3, Harter V4, Verhaeghe JL, et al (2014) Granulosa cell tumor of the ovary: retrospective study of 17 cases. Gynecol Obstet Fertil 42(5): 331-333.

50. Lee IH, Choi CH, Hong DG, Song JY, Kim YJ, et al. (2011) Clinicopathologic characteristics of granulosa cell tumors of the ovary: a multicenter retrospective study. J Gynecol Oncol 22(3): 188-195.

51. Poma PA (1998) Hemoperitoneum in a postmenopausal woman. J Nat Med Assoc 90(5): 317-319. 
52. Ozols RF (1992) Ovarian cancer, Part II: Treatment. Curr Probl Cancer 16(2): 61-126.

53. Lavery JP, Sanfilippo JS (2012) Pediatric and adolescent obstetrics and gynecology. Springer Science \& Business Media, Berlin, Germany, p. 362.

54. King LA, Okagaki T, Gallup DG, Twiggs LB, Messing MJ, et al. (1996) Mitotic count, nuclear atypia, and immunohistochemical determination of Ki-67, c-myc, p21-ras, c-erbB2, and p53 expression in granulosa cell tumors of the ovary: mitotic count and Ki-67 are indicators of poor prognosis. Gynecol Oncol 61(2): 227-232.

55. Bristow RE, Karlan BY (2005) Surgery for Ovarian Cancer: Principles and Practice. CRC Press, USA.

56. Nosov V, Silva I, Tavassoli F, Adamyan L, Farias-Eisner R, et al. (2009) Predictors of recurrence of ovarian granulosa cell tumors. Int J Gynecol Cancer 19(4): 628-633. 